Original Article

\title{
PREPARATION AND EVALUATION OF IRON OXIDE NANOPARTICLES FOR TREATMENT OF IRON DEFICIENCY ANEMIA
}

\author{
FAHIMA HASHEMa, MOHAMED NASRa , YOMNA AHMED
}

aProfessor of Pharmaceutics and Industrial Pharmacy, Faculty of Pharmacy, Helwan University, Cairo, Egypt, bGraduate Student at the Department of Pharmaceutics and Industrial Pharmacy, Faculty of Pharmacy, Helwan University, Cairo, Egypt

Email: yomnamoussa9@gmail.com

Received: 20 Sep 2017 Revised and Accepted: 22 Nov 2017

\section{ABSTRACT}

Objective: The objective of this research was to formulate and evaluate iron oxide nanoparticles for treatment of iron deficiency anemia (IDA).

Methods: Iron oxide nanoparticles were prepared by co-precipitation method and stabilized by coating with folic acid or chitosan. The prepared nanoparticles were characterized in vitro for morphology, particle size, zeta potential, crystallinity and ultraviolet-visible (UV-Vis) absorption. In vivo studies were performed to evaluate the efficacy of the prepared nanoparticles in treating iron-deficient anemic rats compared to the commercial iron product.

Results: In vitro results revealed that particle sizes were $65.95 \pm 5 \mathrm{~nm}, 220.2 \pm 12 \mathrm{~nm}$ and $295.3 \pm 19 \mathrm{~nm}$ for uncoated iron oxide nanoparticles, folic acid-coated iron oxide nanoparticles and chitosan coated iron oxide nanoparticles, respectively. UV-Vis absorption spectrum and x-ray diffraction (XRD) patterns confirmed that the prepared nanoparticles were iron oxide nanoparticles. In vivo results indicated that folic acid-coated iron oxide nanoparticles showed effective restorative action, returning haemoglobin $(\mathrm{Hb})$ concentration to normal levels, where not only complete recovery of $\mathrm{Hb}$ within short time from the anemic state to the high normal level, but also improved $\mathrm{Hb}$ concentrations compared to the commercial iron product.

Conclusion: The results obtained in this research work clearly indicated a promising potential of folic acid-coated iron oxide nanoparticles for the effective treatment of IDA.

Keywords: Iron deficiency anemia, Iron oxide nanoparticles, Folic acid, Chitosan

(C) 2018 The Authors. Published by Innovare Academic Sciences Pvt Ltd. This is an open access article under the CC BY license (http://creativecommons.org/licenses/by/4.0/) DOI: http://dx.doi.org/10.22159/ijpps.2018v10i1.22686

\section{INTRODUCTION}

Iron deficiency anemia (IDA) is the most common nutritional disorder in which the capacity of blood to deliver oxygen to body cells and tissues is reduced [1-3]. It's possible to have the symptoms for years without ever knowing the cause. A lot of people don't know that they suffer from IDA. The diagnosis of IDA is confirmed by the findings of low iron stores and $\mathrm{Hb}$ level below normal. In women of childbearing age, loss of iron in the blood due to heavy menstruation, pregnancy, inadequate iron intake and decreased iron absorption are the most common causes of IDA [4].

Doctors normally treat the condition with iron supplements and changes in diet [5]. Ferric and ferrous iron salts are the most commonly used iron supplements such as ferrous sulfate, ferric citrate, ferrous gluconate and ferric sulfate [6]. Treatment of IDA with iron supplements may be limited as they are associated with gastrointestinal side effects such as constipation, nausea, abdominal discomfort and dark colored stool. Delayed-release and enteric-coated iron supplements have been developed to increase patient compliance as they cause fewer side effects; however, they are not as well absorbed as the non-enteric coated preparations [7].

Nanoparticles have emerged as a promising strategy for the efficient delivery of drugs [8-12]. Recent researches on the gastrointestinal absorption of nanoparticles focus on enhancing the absorption of drugs, vaccines and nutrients that either are degraded by the digestive process or poorly absorbed [13, 14]. Several iron nanoparticles formulations were prepared to treat IDA with great efficiency and low side effects instead of the frequently used iron salt $[15,16]$. The objective of this study was to prepare iron oxide nanoparticles and evaluate their potential as an iron supplement in the treatment of IDA compared to a commercial iron preparation.

\section{MATERIALS AND METHODS}

\section{Materials}

Ferric chloride $\left(\mathrm{FeCl}_{3}, 6 \mathrm{H}_{2} \mathrm{O}, 98 \%\right.$ ) was purchased from Alpha chemicals, Mumbai, India. Ferrous sulphate $\left(\mathrm{FeSo}_{4}, 7 \mathrm{H}_{2} \mathrm{O}\right)$ was purchased from nice chemicals Pvt. Ltd., Kerala, India. Ammonia solution (33\%) and phosphoric acid were purchased from El Nasr pharmaceutical chemicals Company, Cairo, Egypt. Chitosan and folic acid were purchased from Sigma-Aldrich (St. Louis, MO, USA) Choline chloride, casein and DL-methionine were purchased from Loba chemie Pvt. Ltd., Mumbai, India. All chemicals were of analytical grade and were used without further purification.

\section{Preparation of iron oxide nanoparticles}

Iron oxide nanoparticles were prepared according to a previously reported method [17] with slight modifications. Briefly, $5 \mathrm{ml}$ ferric chloride $(0.25 \mathrm{M})$ was added to $5 \mathrm{ml}$ ferrous sulfate $(0.25 \mathrm{M})$ and mixed well. A magnetic stirrer was used for stirring the solution for $20 \mathrm{~min}$ at $45^{\circ} \mathrm{C}$ to remove any oxygen dissolved in the preparation. $40 \mathrm{ml}(1 \mathrm{M})$ Ammonia solution was added and the obtained mixture was stirred for a further 30 min until a precipitate was formed. The preparation was centrifuged for $8 \mathrm{~min}$ at $6000 \mathrm{rpm}$, and the precipitate was washed with deionized water. The washing procedure was repeated four times to remove any excess ammonia. The precipitate was directly dried in an oven at $60^{\circ} \mathrm{C}$ for $24 \mathrm{~h}$.

\section{Preparation of folic acid coated nanoparticles}

In an aqueous medium, iron oxide nanoparticles were prepared by mixing $5 \mathrm{ml}$ ferric chloride $(0.25 \mathrm{M})$ with $5 \mathrm{ml}$ ferrous sulfate $(0.25 \mathrm{M})$, and then the mixture was stirred constantly by a magnetic stirrer for $30 \mathrm{~min}$ at $45^{\circ} \mathrm{C}$ to remove any oxygen dissolved in the preparation. Folic acid $(0.2 \mathrm{~g})$ was dissolved in $40 \mathrm{ml}$ Ammonia (1 M), and then added to the preparation. For a further $30 \mathrm{~min}$, the mixture was 
stirred constantly until a precipitate formed. The precipitate was separated by centrifugation and washed four times to remove excess ammonia, then dried in an oven at $60^{\circ} \mathrm{C}$ for $24 \mathrm{~h}$

\section{Preparation of chitosan-coated iron oxide nanoparticles}

The previously prepared uncoated iron oxide nanoparticles were mixed with $10 \mathrm{ml}(0.2 \mathrm{mg} / \mathrm{ml})$ chitosan. The $\mathrm{pH}$ was adjusted to 4.0 by adding a small amount of phosphoric acid, and then stirring was continued for $12 \mathrm{~h}$ by a magnetic stirrer. The prepared nanoparticles were separated by centrifugation and washed four times with deionized water. The precipitate was directly dried in an oven at $60^{\circ} \mathrm{C}$ for $24 \mathrm{~h}$.

\section{Morphology of iron oxide nanoparticles}

Morphological examination of iron oxide nanoparticles was carried out using transmission electron microscope (TEM), (Tecani-G20 microscope, FEI, The Netherlands), equipped with super twin lens, a LaB6 electron source and operated at $60 \mathrm{kV}$. A droplet of iron oxide nanoparticles dispersion was placed on a carbon-coated copper grid, and the excess fluid was removed by an absorbent filter paper. The samples were viewed using magnification up to $1000000 \mathrm{x}$.

\section{Particle size and zeta potential determination}

Particle size, size distribution and zeta potential were measured by (Malvern Zetasizer nano, Worcestershire, UK). The samples were dispersed in deionized water followed by sonication for 5 $\mathrm{min}$, then the prepared nanoparticles were measured triplicates at room temperature using a $45 \mathrm{~mm}$ focus lens and a beam length of $2.4 \mathrm{~mm}$.

\section{X-ray diffraction study (XRD)}

XRD patterns of iron oxide nanoparticles were obtained using (X'PertPRO Diffractometer, PAN alytical, Netherlands). The diffractograms were recorded at room temperature with $\mathrm{Cu}$ as tube anode, under the following conditions: steps were $0.02{ }^{\circ}$ of $\left({ }^{\circ} 2 \theta\right)$, the counting rate was $0.5 \mathrm{~s} / \mathrm{step}$, the current was $30 \mathrm{~mA}$, and the voltage was $45 \mathrm{kV}$. Data

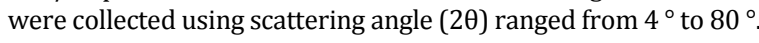

\section{Ultraviolet-visible spectroscopy (UV-Vis)}

Absorption spectrum of uncoated iron oxide nanoparticles was recorded using a spectrometer (Lambda EZ 201, Perkin Elmer, Massachusetts, USA) over the range of 200 to 600 .

\section{In vivo evaluation of iron oxide nanoparticles in treatment of} IDA

This in vivo study was performed to evaluate the potential of iron oxide nanoparticles in the treatment of IDA in rats compared to a commercially available iron supplement product. This study approval was obtained from the Animal Ethics Committee of Faculty of Pharmacy, Helwan University (approval number: 005A-12). The ethics committee guidelines were followed during the study. Thirtytwo female Wistar rats ( $3 \mathrm{w}$ old), weighing $100 \pm 10 \mathrm{~g}$ were used in the study. All rats were maintained in a temperature and light controlled room. Blood samples were withdrawn prior to induction of IDA from the retro-orbital sinus using heparinized glass capillary tubes. Blood samples were analyzed for hemoglobin (Hb) concentration using ABX animal cell counter, Montpellier, France.

The rats were divided randomly into four groups, each of 8 rats. Group (A) was a control group, where rats were fed normal diet during the whole experimental period. The treatment groups $(\mathrm{B}, \mathrm{C}$ and D) were fed iron free basal diet till becoming normal nutritional iron-deficient anemic rats. The anemic rats in each treatment group (B, C and D) were divided into two subgroups (4 rats each) treated with one daily dose of two different doses $(2 \mathrm{mg} / \mathrm{kg}$ and $4 \mathrm{mg} / \mathrm{kg})$ of commercially available iron supplement product containing ferrous sulfate, uncoated iron oxide nanoparticles and folic acid-coated iron oxide nanoparticles, respectively. The doses of all treatments were suspended in $1.0 \%$ carboxymethylcellulose solution and given orally for $4 \mathrm{w}$ with an animal feeding needle. At the end of treatment period, blood samples were collected in heparinized glass tubes and analyzed for $\mathrm{Hb}$ concentration.

\section{Preparation of iron-free basal diet}

Standard iron free basal diet was prepared from fine ingredients. The diet had the following composition per $100 \mathrm{~g}$ : Sunflower oil $10 \%$, salt mixture $4 \%$ [18], vitamin mixture $1 \%$, choline chloride $0.2 \%$, protein $12 \%$, DL-methionine, and cornstarch up to $100 \mathrm{~g}$ [19].

\section{Statistical analysis}

Data are expressed as the menthe standard deviation. Paired t-test was used to analyze the obtained data and any $P$ value less than 0.05 was considered to be statistically significant.

\section{RESULTS AND DISCUSSION}

\section{Morphology of iron oxide nanoparticles}

TEM images of the uncoated iron oxide nanoparticles (fig. 1A) showed spherically shaped particles with average diameter of $8.33 \pm 1.64 \mathrm{~nm}$ which is in good agreement with previous research [16]. The folic acid coated (fig. 1B) and chitosan coated iron oxide nanoparticles (fig. 1C) were similar in shape but larger in size with aggregations. Similar results have been previously reported [15-17]. The observed aggregations of the coated iron oxide nanoparticles might be due to the incomplete coating of individual particles by folic acid or chitosan [20].
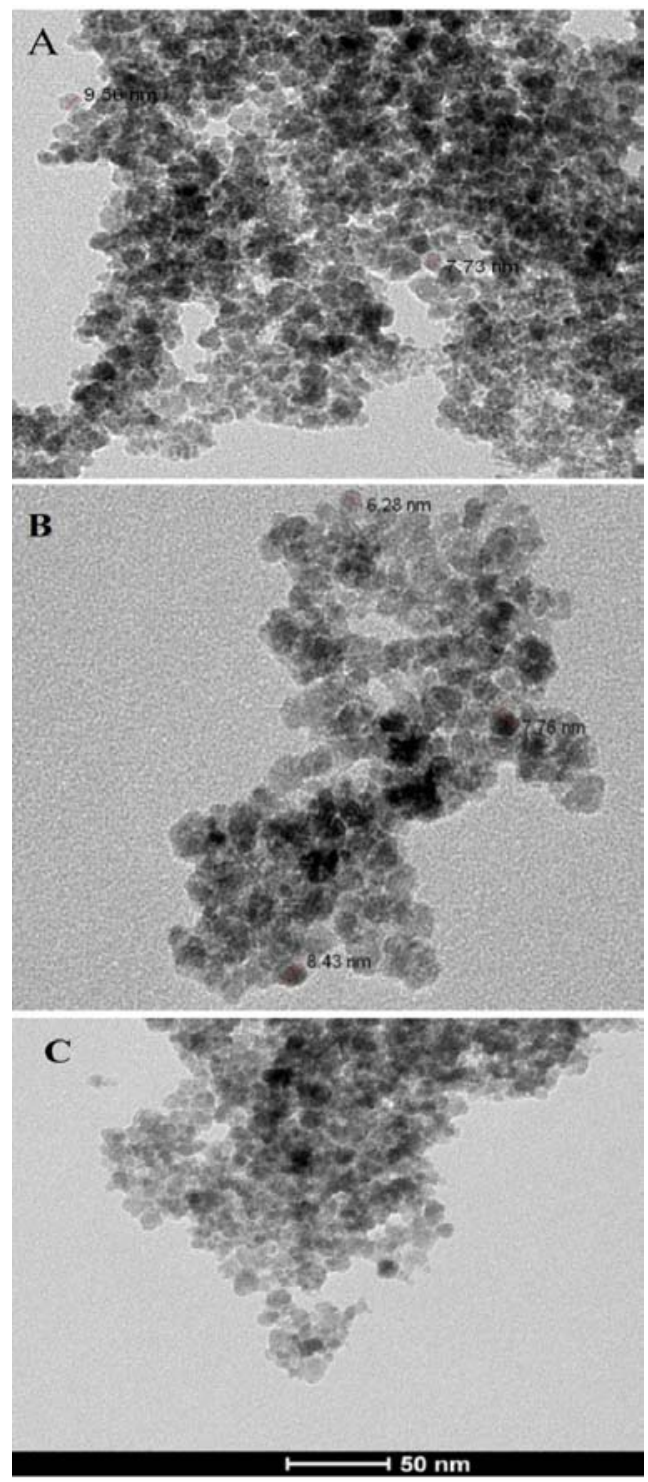

Fig. 1: TEM images of (A) uncoated iron oxide nanoparticles, (B) folic acid-coated iron oxide nanoparticles and (C) chitosan coated iron oxide nanoparticles 


\section{Particle size and zeta potential}

The mean particle size of uncoated iron oxide nanoparticles was $65.95 \pm 5 \mathrm{~nm}$ which is in good agreement with previously reported results [17]. After coating with folic acid and chitosan, the mean particle size increased to $220.2 \pm 12 \mathrm{~nm}$ and $295.3 \pm 19 \mathrm{~nm}$, respectively. The obtained particle sizes of the coated iron oxide nanoparticles are larger than that reported previously for either folic acid-coated [15] or chitosan-coated iron oxide nanoparticles
[17]. The particle size distribution of all samples (fig. 2) showed unimodal patterns. The average zeta potential of the uncoated iron oxide nanoparticles, folic acid-coated iron oxide nanoparticles and chitosan coated iron oxide nanoparticles were-25.6 $\pm 3 \mathrm{mV},-10.9 \pm 1.9$ $\mathrm{mV}$ and $-0.668 \pm 0.1 \mathrm{mV}$, respectively. Similar results were reported previously [17]. The zeta potentials of chitosan-coated iron oxide nanoparticles and folic acid-coated iron oxide nanoparticles are higher than that of uncoated iron oxide nanoparticles due to the highly positive charge of chitosan and folic acid [21].

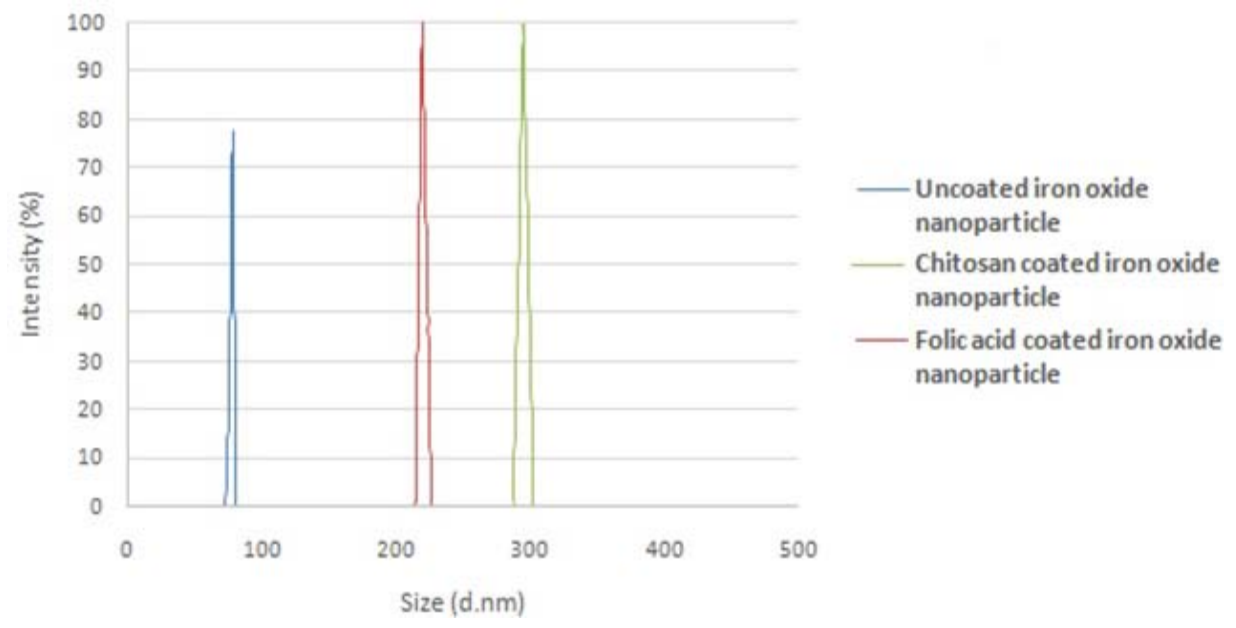

Fig. 2: Particle size distribution curve of the prepared iron oxide nanoparticles

\section{XRD analysis}

XRD patterns of the prepared iron oxide nanoparticles showed the six characteristic peaks of iron oxide at $2 \theta$ values of $30.1,35.5,43.3$, 53.7, 57 and 62.8 (fig. 3). Similar results have been previously reported [22]. Peaks assigned to chitosan $\left(2 \theta=8^{\circ}\right.$ and $\left.20^{\circ}\right)$, and peaks assigned to folic acid $\left(2 \theta=10.2^{\circ}, 12.7^{\circ}\right.$ and $\left.26.6^{\circ}\right)$ were still observed after coating which is similar to previously reported results [23, 24]. Sharp peaks also suggest that the iron oxide nanoparticles have good crystallized structure. Peak widening was consistent with the small particles sizes of the nanoparticles [25].
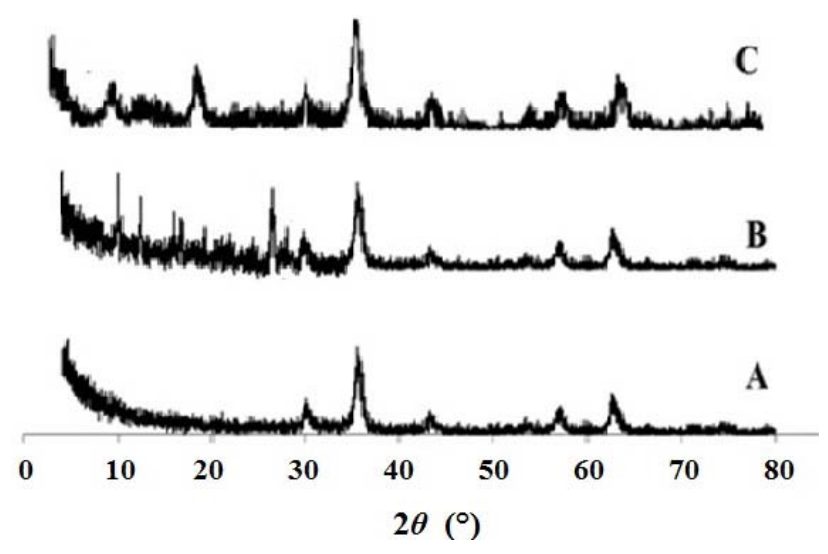

Fig. 3: XRD patterns of $(A)$ uncoated iron oxide nanoparticles, (B) folic acid-coated iron oxide nanoparticles and (c) chitosan coated iron oxide nanoparticles

\section{UV-Vis absorption spectroscope}

The observed UV band (fig. 4) originated primarily from the absorption and scattering of light by iron oxide nanoparticles. The high absorption band of iron oxide nanoparticles at $340 \mathrm{~nm}$ is in good agreement with previous literature [26].

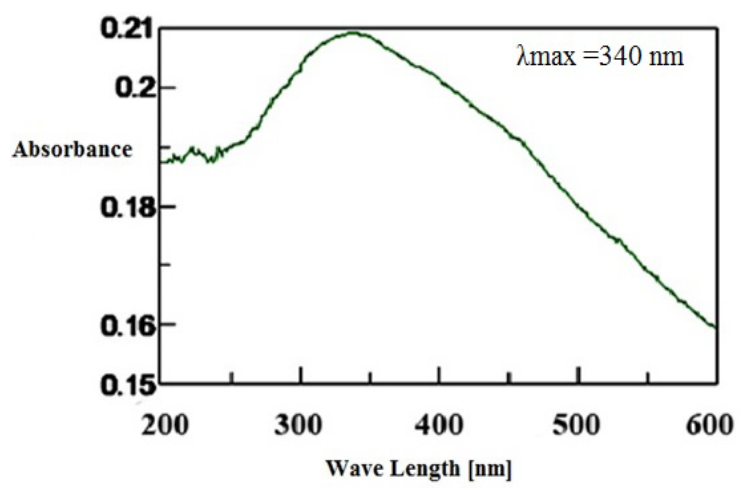

Fig. 4: UV-Vis absorption spectrum of uncoated iron oxide nanoparticles

In vivo evaluation of iron oxide nanoparticles in treatment of IDA

\section{Induction of anemia in rats}

No animal mortality was found in rats during IDA induction period, but some symptoms such as loss of appetite were observed. The effect of iron free diet on $\mathrm{Hb}$ concentration in rats after $6 \mathrm{w}$ of feeding was shown in table (1).

The mean $\mathrm{Hb}$ concentration was reduced by $63 \%$ compared to control rats which suggest successful induction of IDA among the three groups of rats. Similar results have been previously reported $[15,16]$.

\section{Treatment of IDA in rats}

The mean percentage increase in $\mathrm{Hb}$ concentrations in anemic rats were $118.95 \%, 163 \%$ and $294.5 \%$ after $4 \mathrm{w}$ treatment with $2 \mathrm{mg} / \mathrm{ml}$ of commercial iron product, uncoated iron oxide nanoparticles and folic acid-coated iron oxide nanoparticles, respectively. The mean percentage increase in $\mathrm{Hb}$ concentrations in anemic rats were $178.87 \%, 206 \%$ and $297.02 \%$ after $4 \mathrm{w}$ treatment with $4 \mathrm{mg} / \mathrm{ml}$ of 
commercial iron product, uncoated iron oxide nanoparticles and folic acid-coated iron oxide nanoparticles, respectively.

All treatment groups (group B, C and D) showed significant $(P<0.05$, paired t-test $)$ increase in $\mathrm{Hb}$ concentrations in both two doses $(2 \mathrm{mg} / \mathrm{kg}$ and $4 \mathrm{mg} / \mathrm{kg})$ relative to the mean baseline blood $\mathrm{Hb}$ after induction of anemia as shown in table (2) and (3).

Similar results have been previously reported [15].

Table 1: Effect of iron-free basal diet on blood Hb concentrations in rats after $6 \mathrm{w}$

\begin{tabular}{|c|c|c|c|c|}
\hline \multirow[t]{2}{*}{ Week } & \multicolumn{4}{|c|}{ Mean blood hemoglobin (g/dl $\pm S D, n=8)$} \\
\hline & Group (B) & Group (C) & Group (D) & Average \\
\hline 0 & $12.5 \pm 1.1$ & $12.7 \pm 0.9$ & $11.9 \pm 1.5$ & $12.4 \pm 1.2$ \\
\hline 6 & $4.59 \pm 0.59$ & $5 \pm 0.57$ & $4.03 \pm 0.04$ & $4.54 \pm 0.4$ \\
\hline
\end{tabular}

Data are given in mean $\pm \mathrm{SD}, \mathrm{dl}=$ deciliter, $\mathrm{SD}=$ standard deviation, $\mathrm{n}=$ number of rats.

The higher efficacy of iron oxide nanoparticles relative to commercial iron supplement product can be explained by the enhanced bioavailability and therapeutic effectiveness of iron by increasing the surface area. Recent researchers have demonstrated that nanonization of poorly absorbed drugs can improve cellular uptake and oral bioavailability of these drugs $[27,28]$. The increased efficacy of folic acid-coated iron oxide nanoparticles relative to uncoated iron oxide nanoparticles could be explained that coating prevents aggregation of nanoparticles which increases stability and enhances absorption [29].

Table 2: Mean blood $\mathrm{Hb}$ concentrations before and after $4 \mathrm{w}$ of treatment with a dose of $2 \mathrm{mg} / \mathrm{kg}$

\begin{tabular}{lll}
\hline Group of rats & \multicolumn{2}{l}{ Mean blood hemoglobin concentration (g/dl \pm SD, $\mathbf{n = 4 )}$} \\
\cline { 2 - 3 } & Before treatment & After $\mathbf{4}$ w treatment \\
\hline Commercial iron product (B1) & $4.59 \pm 0.59$ & $10.05 \pm 1.5$ \\
Uncoated iron oxide nanoparticles (C1) & $5 \pm 0.57$ & $13.15 \pm 0.5$ \\
Folic acid coated iron oxide nanoparticles (D1) & $4.03 \pm 0.04$ & $15.9 \pm 0.57$ \\
\hline
\end{tabular}

Data are given in mean $\pm \mathrm{SD}, \mathrm{dl}=$ deciliter, $\mathrm{SD}=$ standard deviation, $\mathrm{n}=$ number of rats.

Table 3: Mean blood Hb concentrations before and after $4 \mathrm{w}$ of treatment with a dose of $4 \mathrm{mg} / \mathrm{kg}$

\begin{tabular}{|c|c|c|}
\hline \multirow[t]{2}{*}{ Group of rats } & \multicolumn{2}{|c|}{ Mean blood hemoglobin concentration (g/dl $\pm S D, n=4)$} \\
\hline & Before treatment & After $4 \mathrm{w}$ treatment \\
\hline Commercial iron product (B2) & $4.59 \pm 0.59$ & $12.8 \pm 0.99$ \\
\hline Uncoated iron oxide nanoparticles (C2) & $5 \pm 0.57$ & $15.3 \pm 0.57$ \\
\hline Folic acid-coated iron oxide nanoparticles (D2) & $4.03 \pm 0.04$ & $16 \pm 0.71$ \\
\hline
\end{tabular}

Data are given in mean $\pm \mathrm{SD}, \mathrm{dl}=$ deciliter, $\mathrm{SD}=$ standard deviation, $\mathrm{n}=$ number of rats.

\section{CONCLUSION}

Based on the previous results, iron oxide nanoparticles were successfully synthesized and coated with chitosan and folic acid. The synthesized nanoparticles were spherical shaped particles with a mean size in the range of $65.95 \pm 5$ to $295.3 \pm 19$. In vivo results indicated that iron oxide nanoparticles achieved great success in treating IDA in the experimental animal model, achieving complete recovery of anemic rats from the anemic state to a normal $\mathrm{Hb}$ level within short time. The investigation clearly indicated a promising potential of iron oxide nanoparticles as an iron supplement for the effective treatment of IDA.

\section{AUTHOR CONTRIBUTION}

Fahima Hashem, Mohamed Nasr and Yomna Ahmed designed the study, developed the methodology, collected the data, performed the analysis, and wrote the manuscript.

\section{CONFLICTS OF INTERESTS}

All authors have none to declare

\section{REFERENCES}

1. Baltussen R, Kna C, Sharan M. Iron fortification and iron supplementation are cost-effective interventions to reduce iron deficiency in four subregions of the world. J Nutr 2004; 134:2678-84.

2. Crichton RR, Wilmet S, Legssyer R, Ward RJ. Molecular and cellular mechanisms of iron homeostasis and toxicity in mammalian cells. J Inorg Biochem 2002;91:9-18.
3. Theil EC. Iron, ferritin, and nutrition. Annu Rev of Nutr 2004;24:327-43.

4. Provan D. Mechanisms and management of iron deficiency anaemia. Br J Haematol 1999;105:19-26.

5. Rockey DC. Occult gastrointestinal bleeding. N Engl J Med 1999;341:1477-8.

6. Hurrell R. The mineral fortification of foods. $1^{\text {st }}$ edn Leatherhead: Leatherhead Pub UK; 1999. p. 54-93.

7. Provenzano R, Schiller B, Rao M, Coyne D, Brenner L, Pereira BJG. Ferumoxytol as an intravenous iron replacement therapy in hemodialysis patients. Clin J Am Soc Nephrol 2009;4:386-93.

8. Prema P, Selvarani M. Evaluation of antibacterial efficacy of chemically synthesized copper and zerovalent iron nanoparticles. Asian J Pharm Clin Res 2013;6:222-7.

9. CT, Thangavelu I. Effect of ce3+metal ions on the antibacterial and anticancer activity of zinc oxide nanoparticles prepared by coprecipitation method. Asian J Pharm Clin Res 2017;10:388-92.

10. Yadav N, Khatak S, Sara S. Solid lipid nanoparticles: a review. Int J Appl Pharm 2013;5:8-18.

11. Patil P, Bhoskar M. Optimization and evaluation of spray dried chitosan nanoparticles containing doxorubicin. Int J Curr Pharm Res 2014;6:7-15.

12. Pandey P, Dahiya M. A brief review of inorganic nanoparticles. J Crit Rev 2016;3:18-26.

13. Hoffart V, Lamprecht A, Maincent $P$, Lecompte T, Vigneron C, Ubrich N. Oral bioavailability of a low molecular weight heparin using a polymeric delivery system. J Controlled Release 2006;113:38-42. 
14. Nel A. Toxic potential of materials at the nano level. Science 2006;311:622-7.

15. Elsayed HH, Al-Sherbini ASAM, Abd-Elhady EE, Ahmed KAEA. Treatment of anemia progression via magnetite and folate nanoparticles in vivo. ISRN Nanotechnol 2014:1-13. http://dx.doi.org/10.1155/2014/287575.

16. Salaheldin $\mathrm{T}$, Regheb E. In vivo nutritional and toxicological evaluation of nano-iron fortified biscuits as a food supplement for iron deficient anemia. J Nanomed Res 2016;3:00049.

17. Shi SF, Jia JF, Guo XK, Zhao YP, Chen DS, Guo YY, et al. Biocompatibility of chitosan-coated iron oxide nanoparticles with osteoblast cells. Int J Nanomed 2012;7:5593-602.

18. Hegested DM, Mills RC, Elvehjer CA, Hart EB. Choline in chicks. J Biol Chem 1941;138:459-66.

19. Reeves, Nielsen FH, Fahey GC. AIN-93 purified diets for laboratory rodents: final report of the american institute of Nutrition ad hoc writing committee on the reformulation of the AIN-76A rodent diet. J Nutr 1993;123:1939-51.

20. Mahdavi M, Ahmad M Bin, Haron MJ, Namvar F, Nadi B, Ab Rahman MZ, et al. Synthesis, surface modification and characterisation of biocompatible magnetic iron oxide nanoparticles for biomedical applications. Molecules 2013; 18:7533-48.

21. Hayashi K, Nakamura M, Sakamoto W, Yogo T, Miki H, Ozaki S, et al. Superparamagnetic nanoparticle clusters for cancer theranostics combining magnetic resonance imaging and hyperthermia treatment. Theranostics 2013;3:366-76.
22. Chen Z, Sun Y, Huang P, Yang X, Zhou X. Studies on the preparation of photosensitizer loaded magnetic silica nanoparticles and their anti-tumour effects for targeting photodynamic therapy. Nanoscale Res Lett 2009;4:400-8.

23. Mohseni-Bandpi A, Kakavandi B, Kalantary RR, Azari A, Keramati A. Development of a novel magnetite-chitosan composite for the removal of fluoride from drinking water: adsorption modelling and optimization. RSC Adv 2015; 5:73279-89.

24. Vimala K, Shanthi K, Sundarraj S, Kannan S. Synergistic effect of chemo-photothermal for breast cancer therapy using folic acid (FA) modified zinc oxide nanosheet. J Colloid Interface Sci 2017;488:92-108.

25. Ungar T. Strain broadening caused by dislocations. Mater Sci Forum 1998;278-81:151-7.

26. Ahmad S, Riaz U, Kaushik A, Alam J. Soft template synthesis of superparamagnetic fe304 nanoparticles a novel technique. Inorg Organomet Polym Mater 2009;19:355-60.

27. Hu L, Tang X, Cui F. Solid lipid nanoparticles (SLNs) to improve oral bioavailability of poorly soluble drugs. J Pharm Pharmacol 2004;56:1527-35.

28. Dai J, Nagai T, Wang X, Zhang T, Meng M, Zhang Q. PH-sensitive nanoparticles for improving the oral bioavailability of cyclosporine a. Int J Pharm 2004;280:229-40.

29. Huynh KA, Chen KL. Aggregation kinetics of citrate and polyvinylpyrrolidone coated silver nanoparticles in monovalent and divalent electrolyte solutions. Environ Sci Technol 2011;45:5564-71. 